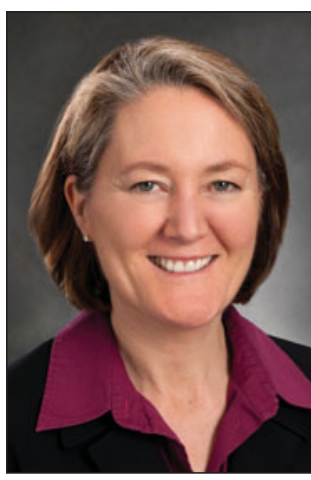

MRS activities this year will be shaped in large part

by you-the MRS members

\section{Worldwide student network}

\author{
www.mrs.org/university-chapters \\ www.mrs.org/foundation
}

Tia Benson Tolle

2014 MRS President

I'm very excited about the coming year and my opportunity to serve as the Materials Research Society President in 2014. As in the past, MRS activities this year will be shaped in large part by you - the MRS members - as we strive to better serve you. One area of increased focus this year will be supporting students, building from programs we've initiated over the last couple of years. After telling you of these efforts, I'd like to explain how you can help our students! MRS is actively working to create a worldwide network of students through the MRS University Chapter Program. We now have over 80 Chapters, having recently recognized students at the University of Alberta (Canada), Khalifa University for Science Research \& Technology (United Arab Emirates), Addis Ababa University (Ethiopia), the African University of Science and Technology (Nigeria), and the University of Cologne (Germany, with the European MRS). We are collaborating with E-MRS, Sociedad Mexicana des Materiales (Mexico), and Sociedade Brasileira de Pesquisa em Materiais (Brazil) to jointly recognize Chapters. And we are now offering free membership to students from institutions in developing countries. But these efforts are just the beginning.

We are seeking to establish sustainable, community-driven programs for engaging and empowering students, with an end goal of a "perpetual environment" for serving students throughout the year, including:

Promoting student-led programs through the Materials Research Society Foundation. In 2013, MRS supported student-proposed, community-based projects at Drexel University, Massachusetts Institute of Technology, Stanford University, University of California-Davis, University of California-Los Angeles, University of Connecticut, University of Delaware, University of Texas at Austin, and Vanderbilt University. These included University Chapter Special Projects for lectures, career days, and undergraduate mentoring as well as Grassroots, Member-Proposed projects for education outreach to middle and high schools.

Enabling meaningful interactions between students with MRS OnDemand ${ }^{\circledR}$. At the 2012 MRS Fall Meeting, we ran the first pilot program using two-way streaming to engage students in Uruguay and Saudi Arabia in the Sustainability Forum in Boston. At the 2013 MRS Fall Meeting, students from Case Western Reserve University, Iowa State University, King Abdullah University of Science and Technology (Saudi Arabia), University of Central Florida, University of Tuskegee, and University of Wisconsin-Eau Claire created a session on Exploration of the Impact of Materials on Society that was live-streamed to MRS University Chapters. 
